\title{
Metabolic Syndrome in Overweight and Obese Children
}

\author{
Mokhammad Ikhsan Nurkholis ${ }^{1}$, Aidah Juliaty A. Baso ${ }^{2}$, Dasril Daud ${ }^{3}$, Johan Setyawan Lisal ${ }^{4}$ \\ ${ }^{1}$ Senior resident, Nutrition \& Metabolic Diseases Division, Department of Pediatrics, Medical Faculty, Hasanuddin University, Makassar, \\ Indonesia
}

${ }^{2}$ Supervisor, Nutrition \& Metabolic Diseases Division, Department of Pediatrics, Medical Faculty, Hasanuddin University, Makassar, Indonesia

${ }^{3}$ Supervisor, Hematology \& Oncology Division, Department of Pediatrics, Medical Faculty, Hasanuddin University, Makassar, Indonesia

${ }^{4}$ Supervisor, Nutrition \& Metabolic Diseases Division, Department of Pediatrics, Medical Faculty, Hasanuddin University, Makassar, Indonesia

\begin{abstract}
Introduction: Obesity and overweight that occurs in childhood tend to persist into adulthood. Chronic Obesity and overweight leads to another condition called metabolic syndrome that strongly associated with Type 2 diabetes and cardiovascular disease. Materials and Methods: A cross-sectional study had been conducted from April until June 2015 on several students of Junior High School in Nusantara's, Athirah's and Frater's in Makassar. The study samples that met the criteria were 80 children of $13-15$ years old students. These samples were divided into two groups: 40 children were overweight and the 40 children were obese. Results: The frequency of metabolic syndrome were higher in the group of obese than the group of overweight children $(p=0.000,0 R 7.000$ with a 95\% CI (2.276 to 21.529). Conclusion: This study indicated that obesity status had a higher incidence of metabolic syndrome than overweight status. Nutritional status was correlated to childhood metabolic syndrome.
\end{abstract}

Keywords: Metabolic Syndrome, Obesity, Overweight, Nutritional, Children

\section{Introduction}

Obesity is defined as an excessive accumulation of fatty tissue that affects health. ${ }^{[1]}$ In past, this disorder is estimated only suffered by people in developed countries. Nowadays the incidence of obesity increased dramatically in neither poor nor the developing countries, including Indonesia. ${ }^{[2]}$

Childhood obesity has tripled in the last 30 years. In the United States, children aged 6-11 years are suffered obese increasing the percentage of $7 \%$ in 1980 to almost $18 \%$ by $2012 .^{[3]}$ The prevalence of overweight and obesity in children aged 6-18 years in Russia is $6 \%$ and $10 \%$, in China was $3.6 \%$ and $3.4 \%$, and in the UK is $22-31 \%$ and $10-$ $17 \%{ }^{[4]}$ The prevalence of obesity in children in Singapore increased from $9 \%$ to $19 \% .{ }^{[5]}$ In Indonesia, the prevalence of obese children nationwide is $14.0 \%$. The figure shows an increase of $12.2 \%$ in 2007 to $14.0 \%$ in 2010 , which there are 12 provinces have problems with high rates of obesity. ${ }^{[6]}$

Obesity occurs because of an imbalance between the intake energy with the output energy, therefore, there is an excess energy stored in the form of fatty tissue. ${ }^{[7]}$ Etiology of obesity in children is due to multifactorial. Genetic and environmental factors play an equally important role as a causative factor. ${ }^{[8]}$ Obesity is characterized by the increase in body mass index (BMI) of children were above 95th percentile on a chart of children's growth according to the sex. Obesity in childhood at the high risk could become obese in adulthood. It also increased the risk of suffering from chronic diseases, among other cardiovascular diseases, diabetes mellitus (DM) type 2, stroke, some types of cancer, and osteoarthritis. ${ }^{[9]}$
In state of overweight and obesity, a growing number of fat cells and fat pad size thicken. This condition is followed by an increase in ROS, which would trigger a chronic inflammation in adiposities cells, by inducing COX-2 inflammatory cytokines (TNF $\alpha$, interleukin 1 (IL-1), IL-6), chemokines (IL-8, CXCR4) and pro -inflammatory transcription factors $(\mathrm{NF}-\mathrm{\kappa B})$. Cytokines that in turn will promote chronic inflammatory heavier with is call more macrophage cells into adiposities. ${ }^{[10]}$ Pre-adiposities cells also play a role in chronic inflammation through the production of monocyte chemo attractant protein-1 (MCP$1)$, the increase is induced from foods that contain high levels of fat. Pre-adipocytes cells produce MCP-1 with the regulations of the AP2 gene that causes insulin resistance, infiltration of macrophages and an increase in hepatic triglyceride. ${ }^{[11]}$

Atherosclerosis is a clinical syndrome that causes the thickening of the artery wall caused by the chronic inflammatory accumulation of white blood cells (WBC) in the artery wall. WBC accumulation is commonly referred to as "fatty streaks", containing the active WBC (induce inflammation), dead cells, as well as LDL cholesterol and triglycerides. Fatty streaks will reduce the elasticity of the arteries, increases blood pressure, and eventually blocked the flow of the blood vessels. The process occurs very slowly, some literature suggests yearly until decades. ${ }^{[12]}$

The concept of the metabolic syndrome was first disclosed by Reaven in 1988, he observed an association of several factors that can increase the incidence of cardio-vascular diseases (CVD) and diabetes mellitus type 2 (DM type 2) in obese adults. A simple understanding of the metabolic syndrome (syndrome $\mathrm{X}$, insulin resistance syndrome, 


\section{International Journal of Science and Research (IJSR) \\ ISSN (Online): 2319-7064}

Index Copernicus Value (2013): 6.14 | Impact Factor (2014): 5.611

Reaven's syndrome) is a condition where an interruption mechanisms of use and energy storage, which is characterized by the occurrence of several medical disorders at the same time as an increase in fasting blood sugar, increased blood pressures, increased waist circumference, increased triglycerides and decreased the levels of HDL. ${ }^{[13]}$

Therefore, it is important to do a study on the effect of nutritional status of children on the incidence of metabolic syndrome. Criteria for metabolic syndrome for children is based on the National Cholesterol Education Program (NCEP) criteria, they obtained at least three out of five of the following symptoms; waist circumference above the $90^{\text {th }}$ percentile, an increase in blood pressure above the $90^{\text {th }}$ percentile, elevated triglycerides $>150 \mathrm{mg} / \mathrm{dL}$, cholesterol decrease $\mathrm{HDL}<40 \mathrm{mg} / \mathrm{dL}$, fasting increased in blood sugar $>100 \mathrm{mg} / \mathrm{dL}$, then the child is categorized suffer from metabolic syndrome. ${ }^{[14]}$ Several studies examined the relationship between obesity and metabolic syndrome has been carried out. ${ }^{[15-17]}$ However, these studies are dominated in adult's cases. While the study on metabolic syndrome in children who suffer from obesity are rarely carried out. The purpose of this study was to determine the frequency of metabolic syndrome in group of overweight and obese children, where the study of this case has never been done in Makassar.

\section{Materials and Methods}

\section{Population}

The study population was selected junior high school students aged 13-15 years derived from the level of middle and upper socio-economic criteria defined by the Education Department of Makassar in order to obtain a high probability of obesity. The selected schools are Junior High School of Nusantara's, Athirah's and Frater's.

The steps undertaken in the selection of the sample is as follows: (1) Collecting data, where first of all make the data of Junior High Schools in Makassar, the identification of the school is based on socioeconomic, selected upper middle class, and recording the number of students in every school; (2) Sampling, each school registered a cluster which will be chosen randomly, the chosen 4 school who represents the group, every class in that school elected a cluster which will be chosen at randomly, chosen again four classes that represent each school, as well as determining the number of students to be sampled in each school were elected proportionally; (3) Take the measurements of weight and height to determine body mass index (BMI) (obesity or overweight), as well as the measurement of abdominal circumference and blood pressure; (4) Then, we take their blood samples for fasting blood sugar, high density lipoprotein (HDL), and triglyceride levels examination of each student to be examined to Prodia laboratory; (5) The inclusion criteria are age 13-15 years (based on the literature) and nutritional status of obese and overweight; (6) The exclusion criteria were good nutritional status, malnutrition and poor nutrition, obesity due to genetic abnormalities/ chromosomal or syndrome (obesity endogenous) determined by physical examination, suffering from chronic kidney disease, diabetes mellitus, hypothyroidism, or hypertension who had received treatment, and got long-term corticosteroid treatment, sitostatika or other drugs that affect body weight. The protocol was conducted in accordance with principles of Good Clinical Practice, including obtaining written informed consent from each participant's parent or legal guardian before study entry, and was approved by the human studies committees applicable to each study site.

\section{Design}

This is a cross sectional study to determine the prevalence of metabolic syndrome in a group of overweight and obese children. The study was conducted from April 2015 to fulfill the desired sample. Examination of blood samples are carried out in Prodia laboratory Makassar. All patients who qualify are recorded: age, sex, height and weight, BMI, blood pressure and stomach circumference. The weight measurement using is calibrated scales that have been trampled to the nearest $0.1 \mathrm{~kg}$. The height measurement using microtoise to the nearest $0.1 \mathrm{~cm}$. Nutritional status is determined based on the calculation of BMI obtained from the weight divided by height squared $\left(\mathrm{kg} / \mathrm{m}^{2}\right)$.

Blood pressure was measured using a mercury sphygmomanometer in accordance with the standard method of National High Blood Pressure Education Program Working Group on High Blood Pressure in Children and Adolescents in 2004. Blood pressure measurement is done after the child is resting in a sitting position for at least 5 minutes, blood pressure was measured in the right arm in the sitting position with the backrest, feet flat on the floor, and the forearm is placed on the table so that the upper arm is at heart level. The measurement is done by auscultation and using a cuff corresponding to the size of the upper arm. 3 measurements carried out at intervals of 1 minute and take the average value. The average yield is then adjusted to the blood pressure table by sex, age, and height percentile. Abdominal circumference was measured in the standing position. The measurements were taken at midway between the lowest arches of caste and the peak top of the iliac crest at the end of normal expiration. The measurement of fasting blood sugar levels, HDL cholesterol, and triglycerides in the blood analyzer are using a Cobas Integra 400 Plus with Chemilumenescence method.

Clinical and laboratory parameters were evaluated: (1) abdominal circumference (2) blood pressure (3) fasting plasma glucose (4) levels of HDL cholesterol (5) triglyceride levels.

\section{Objectives}

The primary objectives were to (1) Determine the prevalence of metabolic syndrome in overweight children groups; (2) Determine the prevalence of metabolic syndrome in obese children group; and (3) Comparing the occurrence frequency of the metabolic syndrome in obese and overweight groups. The secondary objectives were to determine the frequency of the metabolic syndrome in obese and overweight groups.

The obtained data are grouped by its type of data into group of overweight and obese then analyzed each of the 


\section{International Journal of Science and Research (IJSR) \\ ISSN (Online): 2319-7064 \\ Index Copernicus Value (2013): 6.14 | Impact Factor (2014): 5.611}

appropriate statistical methods, including the analyses of univariate and bivariate.

\section{Results}

\section{Sample Characteristics}

In Table 1 shows the characteristics of samples were assessed in the form of sex, age, weight, height and BMI. For the category of sex was found $45(56.25 \%)$ samples of male and $35(43.75 \%)$ samples of female. For the age categories in the obese group obtained 13.66 median, mean 13.77, range from 13.08 to 14.83 years and 0.49 of standard deviations; whereas the overweight group obtained 13.80 median, mean 13.88 , range from 13.10 to 15.00 years and
0.48 of standard deviations. In weight categories, the obese group obtained 72.25 median, mean 73.95 , range $54-105 \mathrm{Kg}$ and standard deviations 11.34; whereas the overweight group obtained 62.25 median, mean 62.14 , range $51-77 \mathrm{~kg}$ and 6.54 standard deviations. For the category of height, in the obese group obtained a median of 1.56 , mean 1.56 , range 1.43 to 1.76 meters and 0.07 standard deviations; whereas the overweight group obtained a median of 1.56, mean 1.57, range 1.45 to 1.72 meters and 0.06 standard deviations. In BMI categories, the obese group obtained 29.82 median, mean 30.29 , range from 24.98 to $40.50 \mathrm{~kg} / \mathrm{m}^{2}$ and 3.37 standard deviations; whereas the overweight group obtained 25.37 median, mean 25.19 , range of 22.34 to $27.85 \mathrm{~kg} / \mathrm{m}^{2}$ and 1.28 standard deviations.

Table 1: Study Characteristics

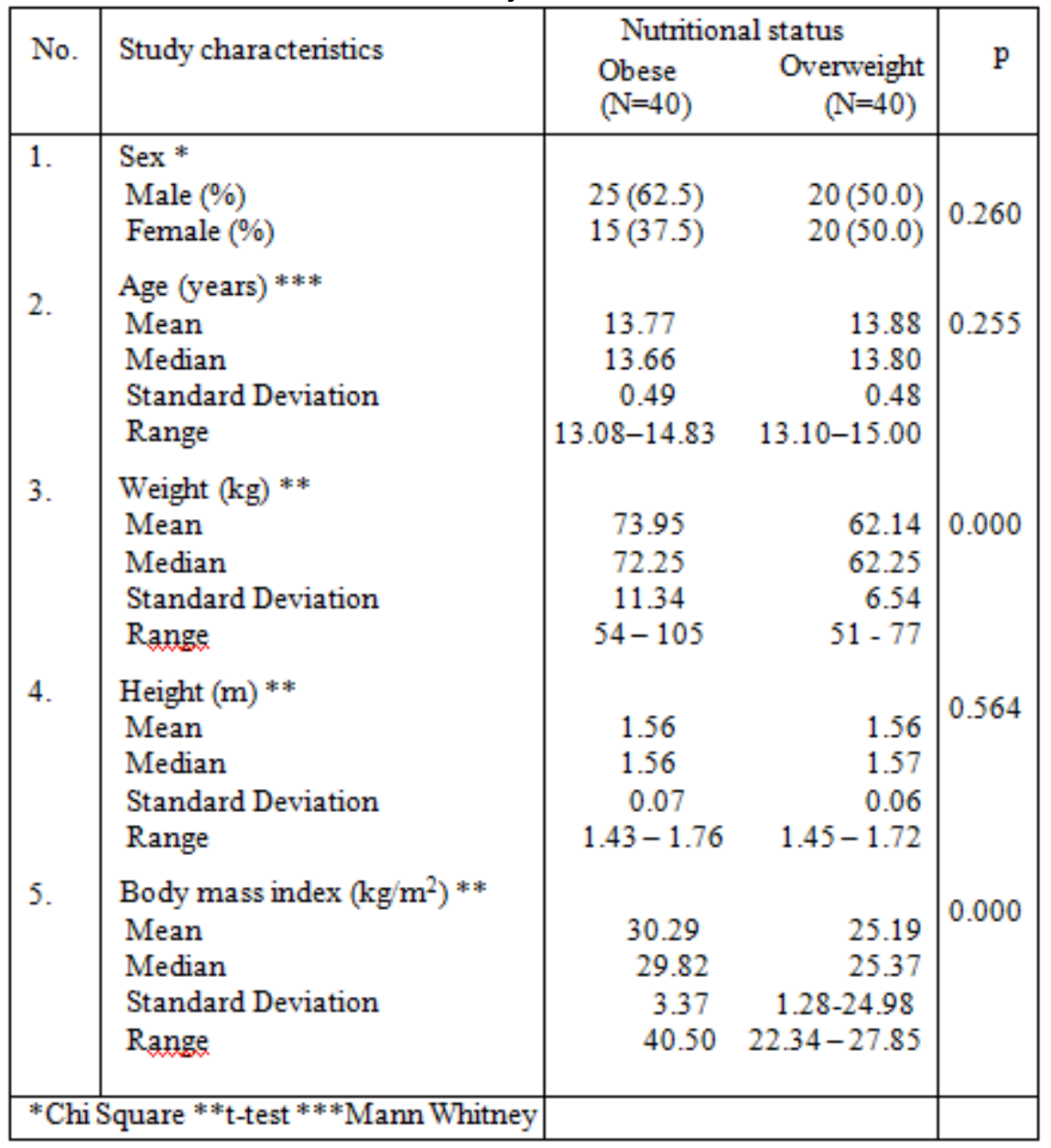

Chi Square test results analyses frequency of occurrence of the metabolic syndrome showed significant differences with $p=0.000(p<0.05)$ between the group of obese among the overweight children (Table 2 ) with odd ratio $(\mathrm{OR})=7.000$ and $95 \%$ CI $(2.276$ to 21.529$)$. Twenty-two children obtained the metabolic syndrome in obese children, with the distribution criteria for the metabolic syndrome as follows as Trig + LP + blood pressure + fasting blood sugar + HDL $(15 \%), \mathrm{LP}+$ Trig + fasting blood sugar + HDL (5\%), LP + Trig + blood pressure + HDL (10\%), LP + Trig + blood pressure + fasting blood sugar $(10 \%)$, LP + Trig + blood pressure $(35 \%)$, LP + Trig + fasting blood sugar (5\%), LP + Trig + HDL $(5 \%)$ and LP + blood pressure + fasting blood sugar $(15 \%)$. Whereas in the group of overweight children gained 5 children with metabolic syndrome distribution of metabolic syndrome criteria as follows as Trig + blood pressure + fasting blood sugar + HDL $(20 \%)$, Trig + blood pressure + fasting blood sugar (20\%), Trig + blood pressure + HDL (20\%) and Trig + fasting blood sugar + HDL (20\%).

Table 2: Relationship of metabolic syndrome with nutritional status

\begin{tabular}{|c|c|c|c|c|}
\hline \multirow{2}{*}{$\begin{array}{c}\text { Metabolic } \\
\text { syndrome }\end{array}$} & \multicolumn{2}{|c|}{ Nutritional status } & \multirow{2}{*}{ OR } & \multirow{2}{*}{ CI 95\% } \\
\cline { 2 - 3 } & Obese & Overweight & & \multirow{2}{*}{ Yes } \\
\hline No & $20(50 \%)$ & $5(12.5 \%)$ & & \multirow{2}{*}{$20(50 \%)$} \\
\hline Total & $45(87.5 \%)$ & \multirow{2}{*}{7.000} & $2.276-21.529$ \\
\hline & $40(100 \%)$ & $40(100 \%)$ & & \\
\hline
\end{tabular}




\section{International Journal of Science and Research (IJSR) \\ ISSN (Online): 2319-7064}

Index Copernicus Value (2013): 6.14 | Impact Factor (2014): 5.611

\section{Discussion}

This is a cross sectional study in 80 children who were divided into 2 groups: $40(50 \%)$ obese children and 40 $(50 \%)$ of overweight children. The analyses frequency of occurrence in metabolic syndrome in the group of obese children is 7 times higher than the group of overweight children. It can be concluded that there is a correlation between the incidences of metabolic syndrome with nutritional in obesity and overweight status.

In this study, the sample is taken from adolescents 13-15 years of age (junior high school students), with the possibility to obtain the prevalence of obesity and overweight is greater than the younger children. The advantages sampling of 13-15 years age limit, among others: the growth of fat tissue is more stable, more cooperative in performing the procedure fasting before blood sampling, closer to the adult age in which the cut-off point to determine fasting blood sugar, high triglycerides, and low HDL cholesterol, an age range based on NCEP ATP III, 2002. The cohort study by Wright et al. which examines the impact of childhood obesity on the risk of obesity in adulthood were performed on a child in 1142, reported that only obese children at age 13 years and over who showed an increased risk of obesity in adulthood $(p=0.014) .{ }^{18}$

In this study we found no statistically significant differences in the sex ratio of male and female on the nutritional status with a value of $p=0.260(p>0.05)$, which means that $\operatorname{sex}$ did not affect the nutritional status. This means that sex does not give a bias in the analyses of the metabolic syndrome among the group of obese and overweight children. This is consistent with the data from the National Health and Nutrition Examination Survey in 2002 that conducted a survey in 8814 adolescents in the United States, which said there was no influence of sex on nutritional status. ${ }^{19}$

Results of the analyses of the frequency of metabolic syndrome in the group of obese children is higher than the group of overweight children $(\mathrm{p}=0.000$, OR 7.000 with a $95 \%$ CI (2.276 to 21.529). The frequency of metabolic syndrome in obese children is higher than in overweight children with $\mathrm{p}=0.000(\mathrm{p}<0.05)$. These results are supported from a study conducted by Marcus et al. Viggiano et al. and Chen et al. which showed that the frequency of occurrence of the metabolic syndrome in obese children is higher compared with the overweight children with $\mathrm{p}$ $<0.005^{15,16,20}$

Metabolic syndrome is a condition where an interruption mechanism and the use of energy storage, which is characterized by the occurrence of multiple concurrent medical disorders such as increased fasting blood sugar, increased blood pressure, increased waist circumference, elevated triglycerides and decreased levels of HDL. ${ }^{13}$ Based on the NCEP enhanced by the AHA, metabolic syndrome diagnosis can be obtained when at least three of the following five symptoms; waist circumference above the $90^{\text {th }}$ percentile, an increase in blood pressure above the $90^{\text {th }}$ percentile, elevated triglycerides $>150 \mathrm{mg} / \mathrm{dL}$, cholesterol decrease $\mathrm{HDL}<40 \mathrm{mg} / \mathrm{dL}$, increased fasting blood sugar
$>100 \mathrm{mg} / \mathrm{dL}$, then the child is categorized suffer from metabolic syndrome. ${ }^{14}$

At 40 obese children, there were 20 children $(50.00 \%)$ who have the metabolic syndrome. From the group of obese children who suffer from metabolic syndrome, it was found that the highest frequency of $7(35 \%)$ children with a criteria for improvement abdominal circumference $\mathrm{P}>90+$ blood pressure $\mathrm{P}>90+$ and high levels of triglycerides $>150 \mathrm{mg} /$ dl. Then the frequency with full blown criteria contained in $3(15 \%)$ children with criteria Abdominal Circumference $\mathrm{P}$ $>90+$ Blood Pressure P $>90+$ fasting blood sugar $>100 \mathrm{mg} /$ $\mathrm{dL}$, triglycerides $>150 \mathrm{mg} / \mathrm{dL}$ and low HDL levels $<40$ $\mathrm{mg} / \mathrm{dl}$. Whereas the overweight group (40 children), there were $5(12.5 \%)$ of children suffering from metabolic syndrome. Two $(40 \%)$ children had metabolic syndrome criteria: triglyceride levels $>150 \mathrm{mg} / \mathrm{dl}+$ fasting blood sugar $>100 \mathrm{mg} / \mathrm{dl}+$ HDL levels $<40 \mathrm{mg} / \mathrm{dl}$. Obtained $1(20 \%)$ children had metabolic syndrome criteria: triglyceride levels $>150 \mathrm{mg} / \mathrm{dl}$ blood pressure $+\mathrm{P}>90$ and fasting blood glucose level $>100 \mathrm{mg} / \mathrm{dl}$. There is one $(20 \%)$ children had metabolic syndrome criteria: triglyceride levels $>150$ $\mathrm{mg} / \mathrm{dl}$ blood pressure $+\mathrm{P}>90$ and HDL levels $<40 \mathrm{mg} / \mathrm{dl}$.

In contrast to other diseases this can usually be easily recognizable symptoms, not the case with people who have the metabolic syndrome. Children still look like other healthy children. Patients do not feel any symptoms at all; children still go to school, play sports even. But medically can be said that child is carrying a "time bomb", which in time will eventually give the risk of diabetes mellitus and the possibility of getting coronary heart abnormalities in 10- 15 years. The absence of typical symptoms as a result of the metabolic syndrome in children, making children's need for examination of lipid profile, blood sugar, blood pressure and anthropometric regularly. Examination is recommended as the levels of HDL cholesterol, triglycerides, fasting blood sugar and LP.

Limitations of this study is on a diet, researchers could only partially control the food intake of the study sample with fasting and inspection procedure carried out homogeneously, namely at 08.00 am by the time the child has rested and have not done any physical activity prior to blood sampling for examination profile lipid. However, changes in HDL and triglyceride levels is a condition that takes time, up to the value of HDL and TG were measured by cross-sectional may be a reflection of a process that has been going on long before.

Another limitation of this study is the researchers did not do a status check to test the puberty. At puberty, the dynamic changes in anthropometric children. Female waist circumference at puberty will be wider than the pre-pubertal. Serum lipid levels also reached the peak at the age of 9-10 years and the levels decreased. Decreased total serum cholesterol levels between the ages of 10-16 years in male and age of 9-14 years in female. Picture of the levels of lipid profiles adulthood mirrored by lipid profile picture at the end of puberty. Decreased levels of HDL cholesterol and LDL cholesterol are associated with the increased of testosterone in male and estradiol in female. The results study by The Bogalusa Heart Study showed a negative 


\section{International Journal of Science and Research (IJSR) \\ ISSN (Online): 2319-7064}

Index Copernicus Value (2013): 6.14 | Impact Factor (2014): 5.611

correlation between testosterone levels and HDL cholesterol in adolescent male puberty status in stage I-II by Tanner. The positive correlation between testosterone levels with HDL cholesterol and between testosterone and Apo A1 levels was found in adolescent male with puberty status at a higher stage according to Tanner. Based on previous studies, the adolescent female showed levels of HDL cholesterol were not different at each stage of puberty or the age at menarche.

The selected schools in our study have a School Health Unit which is running smoothly; therefore, both of teachers, parents, and students have an attention to improve their health. The results of this study are expected to be a warning for all parties concerned of the danger of metabolic syndrome that has occurred in childhood. We provide a feedback to schools and parents to improve the preventive efforts on the nutritional status of children either obese or overweight. Our data in this study may be the initial study to conduct further studies with a cohort that follows the path of a study subject, or may intervene resulting in changes in diet, patterns activity more depth.

\section{Conclusion}

Based on the results of this study, we concluded that the frequency of metabolic syndrome occurrence in the group of obese children is 7 times higher than the group of overweight children.

\section{Future Scope}

To find out more about the role of obesity and overweight on the incidence of the metabolic syndrome, it is necessary to do a cohort study and controlling factors that may affect the metabolic syndrome.

\section{References}

[1] Jahari A. Nutritional Status Assessment Based on anthropometry. Bogor: Center for Nutrition and Food. 2004

[2] WHO. Obesity: Preventing and Managing the Global Epidemic. WHO Technical Report Series. Geneva. 2012; 894.

[3] Ogden CL, Carroll MD, Kit BK, Flegal KM. Prevalence of childhood and adult obesity in the United States, 2011-2012. Journal of the American Medical Association. 2014; 311 (8): 806-814.

[4] Wang Y. Cross-national comparison of childhood obesity: the epidemic and the relationship between obesity and socioeconomic status. Int $\mathrm{J}$ Epidemiol. 2007; 30: 1129-1136.

[5] Yap MA, Tan WL. Factors associated with obesity in primary-school children in Singapore. Asia Pacific J Clin Nutr. 1994; 3: 65-68.

[6] Riskesdas. Agency for Health Research and Development of the Ministry of Health of the Republic of Indonesia 2013. 2010

[7] Sjarif D. Obesity in children and their problems. Hot topics in pediatrics II. Jakarta: Indonesia University
Medical Faculty Hospital. Dr. Ciptomangunkusumo. 2002; 219-34

[8] Naamsyah D. Obesity in children: effects and treatment. Medicine magazine, Damianus. 2008; 7: 55-63.

[9] Rockville MD. Office of the Surgeon General: The Surgeon General's Vision for a Healthy and Fit Nation. U.S. Department of Health and Human Services. 2010

[10] Kim J, Montagnani M, Koh KK, Quon MJ. Reciprocal Relationships between Insulin Resistance and Endothelial Dysfunction. Circulation Journal of American Heart Association. 2006; 113:1888-1904.

[11] Hajime K, Tateya S, Tamori Y, et al. MCP-1 contributes to macrophage infiltration into adipose tissue, insulin resistance, and hepatic steatosis in obesity. The Journal of Clinical Investigation. 2006; 116:6

[12]Ross R. Mechanism of disease: Atherosclerosis - an inflammatory disease. The New England Journal of Medicine. 2005; 340:2.

[13] Druet C, Dabbas M, Baltakse V, et al. Insulin resistance and the metabolic syndrome in obese France children. Clin Endocrinol (Oxf). 2006; 6:672-8

[14] Grundy SM, Hansen B, Smith SC, Cleeman JI, Kahn RA. Definition of Metabolic Syndrome: report of the National, Heart, Lung and Blood Institute/ American Heart Association conference on scientific issues related to definition. Circulation. 2006; 109:433-438.

[15] Viggiano D, De Filippo G, Rendina D, et al. Screening of metabolic syndrome in obese children: a primary care concern. J Pediatr Gastroenterol Nutr. 2009; 49: 329334

[16]Chen F, Wang Y, Shan X, et al. Association between Childhood Obesity and Metabolic Syndrome: Evidence from Large Sample of Chinese Children and Adolescents. PLoS ONE Journal. 2012; 7(10): e47380.

[17] Haris S, Tambunan T. Hipertensi pada Sindrom Metabolik. Sari Pediatri. 2009; 11(4):257-63

[18] Wright CM, Parker L, Lamont D, Crjhaft AW. Implications of childhood obesity for adult health: findings from thousand families' cohort study. 2001; 1 ; 323 (7324): 1280-1284.

[19] Noora Mattson. Metabolic syndrome in young adults: Prevalence, childhood predictors and association with subclinical atherosclerosis. Department of Medicine and the Department of Clinical Physiology and Nuclear Medicine, University of Turku, Finland. 2012; 1-96.

[20] Markus J. Childhood Adiposity, Adult Adiposity, and Cardiovascular Risk Factors. The New England journal of medicine. Nejm.org. 2011; 1876-84." 